\title{
Photochemical Studies in Flash Photolysis. II. Photolysis of Acetone with Filtered Light*
}

\author{
N. Slaggt and R. A. Marcust \\ Department of Physical Chemistry, Polytechnic Institute of Brooklyn, Brooklyn, New York
}

(Received August 8, 1960)

\begin{abstract}
Flash photolysis was studied in the absence of wavelengths below $200 \mathrm{~m} \mu$. Effects of acetone pressure, light intensity, added biacetyl, temperature, and wavelength were investigated. The results are consistent with primary acts postulated previously on the basis of low-intensity studies, but with the absence of complicating first-order secondary reactions at these high radical concentrations. Deactivation of excited molecules explains the pressure effect on the $\mathrm{C}_{2} \mathrm{H}_{6} / \mathrm{CO}$ ratio, for wall effects are absent under flash conditions. A hot radical mechanism is suggested by the data for methane formation. The effect of wavelength on $\mathrm{C}_{2} \mathrm{H}_{6} / \mathrm{CO}$ ratio in regions centered near 260,280 , and $295 \mathrm{~m} \mu$ is rather striking, and the results are compared with trends in low-intensity studies in the same pressure region.
\end{abstract}

\section{INTRODUCTION}

$\mathbf{T}$ THE photolysis of acetone has been extensively investigated at low light intensities, ${ }^{1,2}$ and several studies $^{3-5}$ have been made at extremely high intensities under flash conditions. Khan, Norrish, and Porter ${ }^{3}$ flash-photolyzed acetone in the presence of a large amount of inert gas (carbon dioxide) using unfiltered light and found $\mathrm{C}_{2} \mathrm{H}_{6} / \mathrm{CO}$ ratio of unity. Oster and Marcus ${ }^{4}$ also used unfiltered light and observed ratios of about 1.25 in the absence of, but unity in the presence of, excess carbon dioxide. They observed that traces of biacetyl had the same effect and found, too, from the pressure dependence of the $\mathrm{CO}$ quantum yield, that light below $200 \mathrm{~m} \mu$ was contributing effectively to their photolysis and, it may be presumed, to that of Khan et al.

In the present work these wavelengths are removed and the effects of pressure, intensity, temperature, added biacetyl, and wavelength are described. Where feasible, these data are compared with those obtained at $280 \mathrm{~m} \mu$ by Roebber, Rollefson, and Pimentel, ${ }^{5}$ who used a monochromatic (magnesium spark) source. The latter authors' results showed one major apparent difference from low intensity ones-an increased quantum yield of $\mathrm{CO}$ with increased pressure. At low intensities little or no such effect has been found. ${ }^{6-8}$

* Abstracted from the doctoral dissertation of Norman Slagg, Polytechnic Institute of Brooklyn, June, 1960. (Available on microfilm from University Microfilms, Ann Arbor, Michigan.)

Presented in part at the 132nd Meeting of the American Chemical Society, New York City, September, 1957.

† Present Address, Thiokol Corporation, Denville, New Jersey. $\ddagger$ Alfred P. Sloan Research Fellow.

${ }^{\prime}$ Cf. review by E. W. R. Steacie, Atomic and Free Radical Reactions (Reinhold Publishing Corporation, New York, 1954).

${ }^{2}$ Cf. review by W. A. Noyes, G. B. Porter, and J. E. Jolley, Chem. Revs. 56, 49 (1956).

${ }^{3}$ M. A. Khan, R. G. W. Norrish, and G. Porter, Proc. Roy. Soc. (London) A219, 312 (1953),

${ }^{4}$ G. K. Oster and R. A. Marcus, J. Chem. Phys. 27, 472 (1957)

(Part I of this series); cf. R. A. Marcus, Can. J. Chem. 36, 102 (1958), which summarizes several of the results reported in the present paper.

${ }^{5}$ J. L. Roebber, G. K. Rollefson, and G. C. Pimentel, J. Am. Chem. Soc. 80, 255 (1958).

${ }^{6}$ D. S. Herr and W. A. Noyes, J. Am. Chem. Soc. 62, 2052 (1940).

D. E. Hoare, Trans. Faraday Soc. 53, 791 (1957).

J. Heicklen and W. A. Noyes, J. Am. Chem. Soc. 81, 3858 (1959).

\section{EXPERIMENTAL}

\section{Apparatus, Materials, and Analysis}

The flash apparatus was described previously, ${ }^{9}$ the flashing voltage here being $8000 \mathrm{v}$. A cylindrical quartz vessel was used, $2.3 \mathrm{~cm}$ i.d. and $20 \mathrm{~cm}$ long, closed at one end and attached to the vacuum system by a graded seal at the other. The exploding wire ${ }^{4}$ was 32 $\mathrm{cm}$ long, placed parallel to the cylindrical vessel and, except where specified in Table $I, 2.15 \mathrm{~cm}$ distant from the latter's axis. In several experiments, so indicated in Table I, a 7910 Vycor vessel, with an i.d. of $2.6 \mathrm{~cm}$ and a length of $20 \mathrm{~cm}$, was used instead. The wire length employed was then $22 \mathrm{~cm}$. Throughout, the analytical apparatus, procedures, and purification of acetone and biacetyl were the same as in Part $\mathrm{I}$.

\section{Filters}

To effectively eliminate light of wavelengths of 200 $\mathrm{m} \mu$ and less when the quart $z$ reaction vessel was used, the vessel was surrounded with a single layer of du Pont cellophane 450-PD. The vessel plus the cellophane was enclosed in a closefitting protective concentric quartz tube of $2-\mathrm{mm}$ wall thickness. The effectiveness of the cellophane was established from results with two layers of cellophane, which showed essentially no further change in ratios of reaction products. Using the Vycor vessel, which cuts off wavelengths below $220 \mathrm{~m} \mu$, rather similar product ratios were obtained. To obtain wavelengths centered near $260 \mathrm{~m} \mu, 280 \mathrm{~m} \mu$, and $295 \mathrm{~m} \mu$, a suitable concentration of 1,4-diphenylbutadiene in ethanol, one of $\mathrm{CS}_{2}$ in $\mathrm{CCl}_{4}$, and a single layer of 88CA-48 du Pont cellophane, respectively, were used. Transmission curves for these filters are shown in Fig. 1. After the cellophane transmission is multiplied by the extinction coefficient of acetone in this weakly absorbing spectral region, the cellophane is seen, in effect, to provide a wavelength band of about $25 \mathrm{~m} \mu$, centered near $295 \mathrm{~m} \mu$. The filters were placed in a cylindrical Vycor jacket, $5 \mathrm{~cm}$ i.d., and concentric with the $3 \mathrm{~cm}$ o.d. Vycor reaction vessel.

${ }^{9}$ G. K. Oster and R. A. Marcus, J. Chem. Phys. 27, 188 (1957). 
TABLE I. Flash photolysis of acetone with filtered light.

\begin{tabular}{|c|c|c|c|c|c|c|}
\hline \multirow[b]{2}{*}{ Expt 1} & \multicolumn{5}{|c|}{ a. Effect of acetone pressure } & \multirow[b]{2}{*}{$\begin{array}{c}\mathrm{CO} / p_{\mathrm{acot}} \\
\times 10^{3}\end{array}$} \\
\hline & $\begin{array}{l}p_{\mathrm{acet}} \\
(\mathrm{mm})\end{array}$ & $\begin{array}{l}\text { No. of } \\
\text { flashes }\end{array}$ & $\begin{array}{l}\mathrm{CO} / \text { dlash } \\
(\mu \text { moles })\end{array}$ & $\mathrm{C}_{2} \mathrm{H}_{6} / \mathrm{CO}$ & $\mathrm{CH}_{4} / \mathrm{CO}$ & \\
\hline $\begin{array}{r}100^{\mathrm{a}} \\
97^{\mathrm{a}} \\
73^{\mathrm{a}}\end{array}$ & $\begin{array}{l}243 \\
150 \\
100\end{array}$ & $\begin{array}{l}3 \\
3 \\
3\end{array}$ & $\begin{array}{l}0.51 \\
0.37 \\
0.24\end{array}$ & $\begin{array}{l}1.21 \\
1.49 \\
1.66\end{array}$ & $\begin{array}{l}0.10 \\
0.10 \\
0.11\end{array}$ & $\begin{array}{l}2.1 \\
2.3 \\
2.4\end{array}$ \\
\hline $\begin{array}{l}56 \\
48 \\
49 \\
57 \\
37 \\
39 \\
59\end{array}$ & $\begin{array}{c}160 \\
100 \\
100 \\
50 \\
25 \\
9.1 \\
6.7\end{array}$ & $\begin{array}{r}2 \\
2 \\
2 \\
4 \\
10 \\
25 \\
30\end{array}$ & $\begin{array}{l}0.46 \\
0.30 \\
0.28 \\
0.16 \\
0.085 \\
0.026 \\
0.021\end{array}$ & $\begin{array}{l}1.31 \\
1.62 \\
1.65 \\
1.61 \\
1.83 \\
2.26 \\
2.32\end{array}$ & $\begin{array}{l}0.11 \\
0.10 \\
0.11 \\
0.12 \\
0.11 \\
0.11 \\
0.12\end{array}$ & $\begin{array}{l}2.8 \\
3.0 \\
2.8 \\
3.2 \\
3.4 \\
2.9 \\
3.1\end{array}$ \\
\hline
\end{tabular}

b. Effect of incident intensity, $I_{0}$, at $100 \mathrm{~mm}$ acetone ${ }^{b}$

Wire

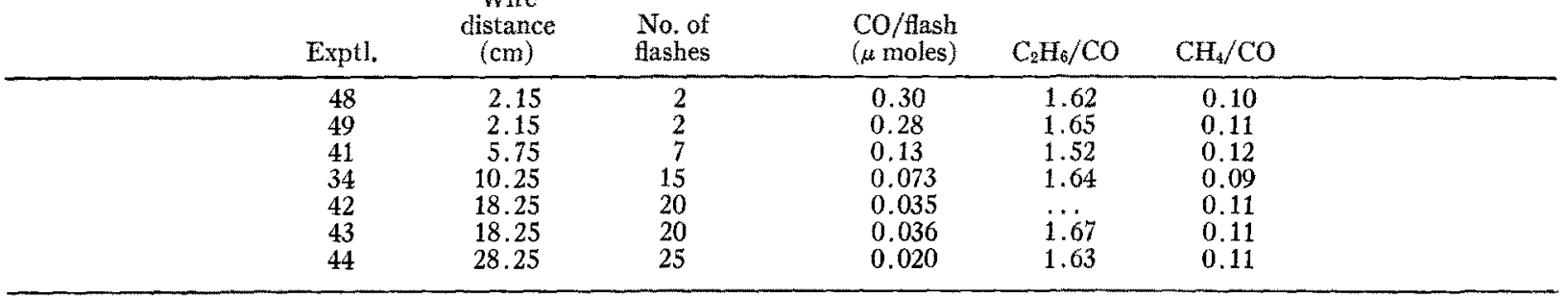

c. Effect of temperature at $100 \mathrm{~mm}$ acetone

\begin{tabular}{ccccccc} 
Exptl & $T\left({ }^{\circ} \mathrm{C}\right)$ & $\begin{array}{c}\text { No. of } \\
\text { flashes }\end{array}$ & $\begin{array}{c}\text { Co/flash } \\
(\mu \text { moles })\end{array}$ & $\mathrm{C}_{2} \mathrm{H}_{6} / \mathrm{CO}$ & $\mathrm{CH}_{4} / \mathrm{CO}^{2}$ \\
\hline 114 & 26 & 4 & 0.15 & 1.64 & 0.11 \\
116 & 25 & 4 & 0.13 & 1.62 & 0.12 \\
113 & 90 & 4 & 0.15 & 1.77 & 0.10 \\
115 & 90 & 4 & 0.14 & 1.81 & 0.11 \\
$141^{\circ}$ & 185 & 1 & 0.68 & 1.86 & 0.09 \\
$140^{\circ}$ & 26 & 1 & 0.78 & 1.70 & 0.12 \\
\hline
\end{tabular}

d. Effect of added biacetyl at $100 \mathrm{~mm}$ acetone

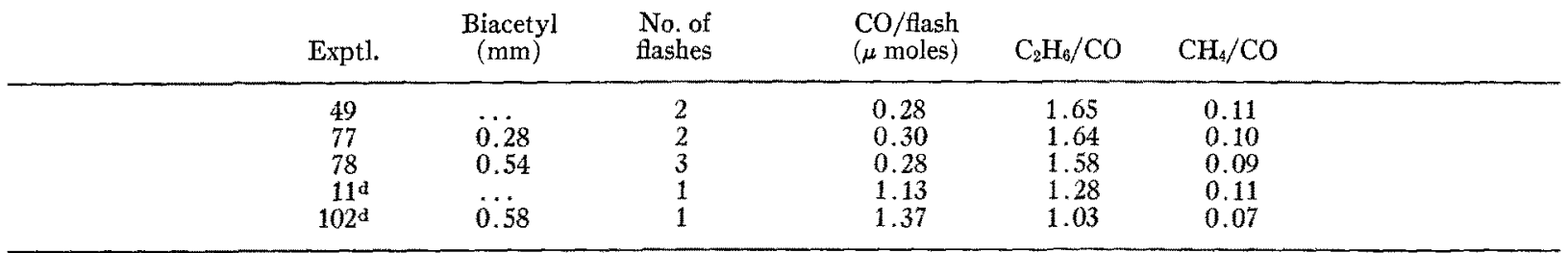

e. Effect of wavelength ${ }^{e}$

\begin{tabular}{cccccccc} 
Exptl. & $\lambda(\mathrm{m} \mu)$ & $\begin{array}{c}\text { Acetone } \\
(\mathrm{mm})\end{array}$ & $\begin{array}{c}\text { No. of } \\
\text { flashes }\end{array}$ & $\begin{array}{c}\text { CO/flash } \\
(\mu \text { moles })\end{array}$ & $\mathrm{C}_{2} \mathrm{H}_{6} / \mathrm{CO}$ & $\mathrm{CH}_{4} / \mathrm{CO}$ \\
\hline 153 & 260 & 100 & 25 & 0.047 & 2.83 & 0.21 \\
163 & 260 & 100 & 25 & 0.052 & 2.67 & 0.17 \\
154 & 260 & 200 & 14 & 0.105 & 1.93 & 0.10 \\
& 136 & 280 & 100 & 15 & 0.046 & 2.26 & 0.11 \\
\\
137 & 280 & 100 & 15 & 0.047 & 2.33 & 0.10 \\
162 & 280 & 200 & 8 & 0.089 & 1.41 & 0.09 \\
\\
138 & 295 & 100 & 16 & 0.037 & 1.23 & 0.12 & 0.11 \\
\hline
\end{tabular}

Experinents 73-116 were performed with a new sample of cellophane 450-PD.

b The intensity is approximately inversely proportional to the distance between wire and vessel axis noted in Table Ib (cf. footnote 9 ). Some deviation would be expected from this "infinite length line source" law at the larger distances because of the finite length effect. For this reason, no CO/I0 ratios were computed.

vycor reaction vessel, wire $2.50 \mathrm{~cm}$ from vessel axis.

d Quartz vessel without cellophane, 450-PD filter.

e Vycor reaction vessel, wire $3.20 \mathrm{~cm}$ from vessel axis. 
FIG. 1. Percent transmission of various filters vs wavelength (liquids have a $1 \mathrm{~cm}$ path length). The transmission curve for the $\mathrm{CS}_{2}$ solution is sensitive to impurities. (A narrower transmission band having the same maximum has been found with purer reagents.) The acetate film $88-\mathrm{CA}-48$ is 0.00088 in. thick and the cellophane $450-\mathrm{PD}$ is $0.0013 \mathrm{in}$.
Fig. 2. Plot of $\mathrm{CO}$ vs acetone pressure, illustrating the importance of wavelengths near $190 \mathrm{~m} \mu$ using unfiltered light.
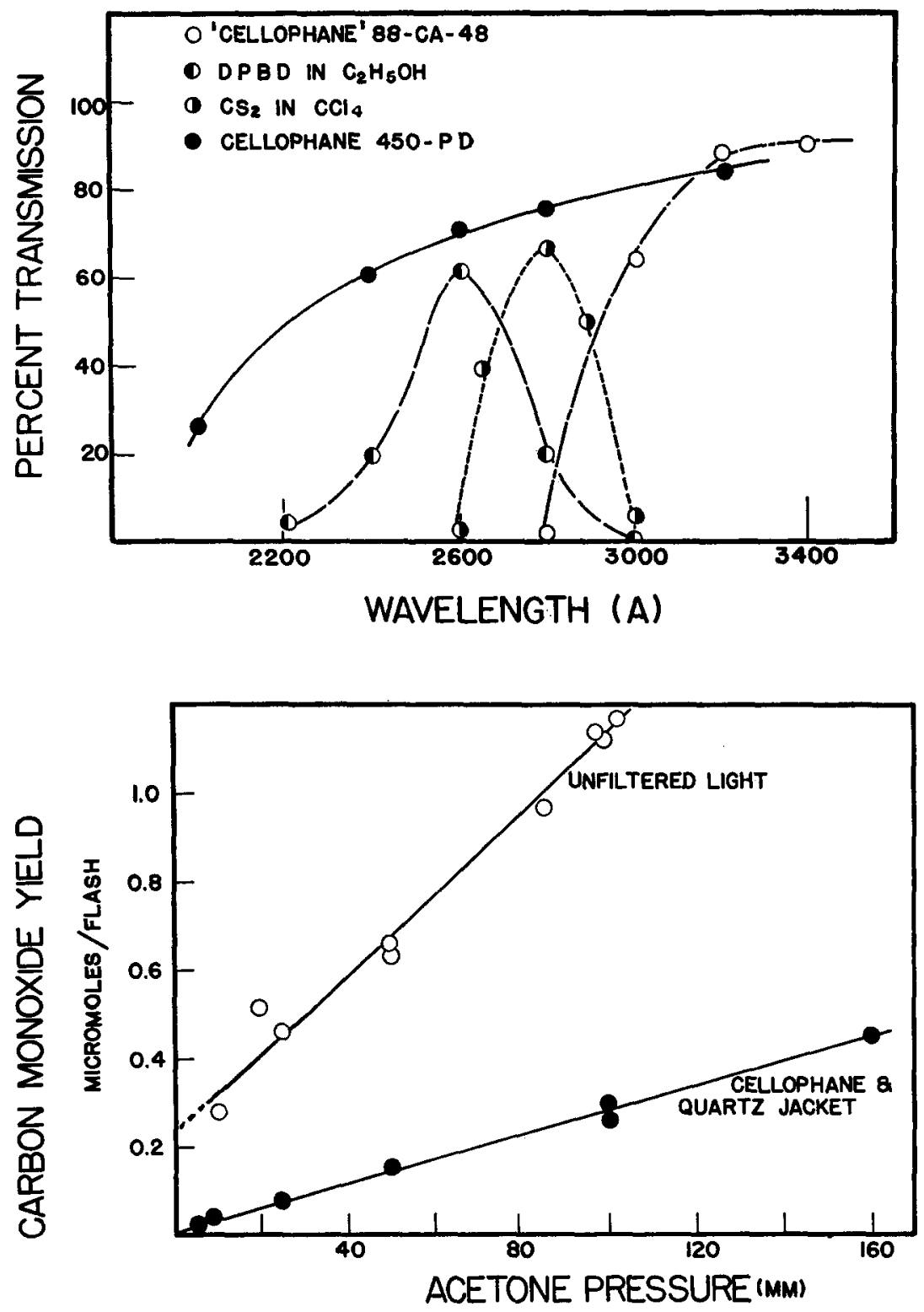

\section{Temperature}

Almost all experiments were performed at room temperature. A temperature of about $90^{\circ} \mathrm{C}$ was obtained with a heated beaker of water and one of $185^{\circ} \mathrm{C}$ with an easily removable asbestos-covered heating coil which jacketed the vessel. At the desired temperature, determined by a thermocouple, the acetone pressure was adjusted, the heating device removed, and the wire moved quickly into place and flashed. The resultant maximum gas temperature drop before flashing, inferred from any gas pressure drop, was less than $8^{\circ} \mathrm{C}$.

\section{RESULTS}

Results obtained at various acetone pressures, intensities, temperature, added biacetyl, and wavelength are given in Table $I$ and Fig. 2. The results may be summarized as follows:

1. When the wavelengths shorter than $200 \mathrm{~m} \mu$ are removed, $\mathrm{CO}$ is directly proportional to the acetone pressure. Hence, because of the small percent light absorption in this region, ${ }^{10} \mathrm{CO}$ is directly proportional to the absorbed light intensity. However, when wavelengths shorter than $200 \mathrm{~m} \mu$ are not removed, the CO vs $p$ plot in Fig. 2 does not extrapolate to the origin, a consequence of the intense acetone absorption near $190 \mathrm{~m} \mu$. The remaining results shown here were obtained in the absence of these short wavelengths.

${ }^{10}$ R. G. W. Norrish, H. G. Crone, and O. D. Saltmarsh, J. Chem. Soc. 1934, 1456; W. A. Noyes, A. B. F. Duncan, and W. M. Manning, J. Chem. Phys. 2, 717 (1934). 
2. Co was essentially independent of temperature and of traces of added biacetyl.

3. The $\mathrm{C}_{2} \mathrm{H}_{6} / \mathrm{CO}$ ratio decreased markedly with increasing pressure. It was independent of incident light intensity, of added biacetyl (unlike the $190 \mathrm{~m}_{\mu}$ data ${ }^{4}$ ), and almost independent of temperature.

4. The $\mathrm{C}_{2} \mathrm{H}_{6} / \mathrm{CO}$ ratio increased with decreasing wavelength in the three regions studied $(260,280,295$ $\mathrm{m} \mu$ ), in the pressure range investigated.

5. The $\mathrm{CH}_{4} / \mathrm{CO}$ ratio was independent of all the preceding variables, except perhaps of wavelength.

6. Two experiments with equal mixtures of acetone and acetone- $d_{6}$ were performed. The ratio $\left(\mathrm{CD}_{4}\right)\left(\mathrm{CH}_{4}\right) /$ $\left(\mathrm{CD}_{3} \mathrm{H}\right)\left(\mathrm{CH}_{3} \mathrm{D}\right)$ was found to be 1.08 and $1.12{ }^{11}$

\section{DISCUSSION}

Comparison of the $\mathrm{C}_{2} \mathrm{H}_{6} / \mathrm{CO}$ ratios in Table $\mathrm{Ia}$ and $\mathrm{b}$ with the corresponding ratios at various wavelengths suggests that our major photochemical contribution is centered near $290 \mathrm{~m} \mu$.

The independence of $\mathrm{CO}$ quantum yield of absorbed light intensity is in agreement with step (1), first suggested by low intensity studies, this step being followed now by radical recombinations only.

$$
\begin{aligned}
&\left(\mathrm{CH}_{3}\right)_{2} \mathrm{CO}+h \mathrm{~h} \rightarrow 2 \mathrm{CH}_{3}+\mathrm{CO} \\
& \text { or } \rightarrow \mathrm{CH}_{3}+\mathrm{CH}_{3} \mathrm{CO}^{\prime} \rightarrow 2 \mathrm{CH}_{3}+\mathrm{CO} .
\end{aligned}
$$

$\mathrm{CH}_{3} \mathrm{CO}^{\prime}$ denotes a hot $\mathrm{CH}_{3} \mathrm{CO}$ whose only fate is to dissociate. At low intensities, $\mathrm{CO}$ is also formed from dissociation of thermally equilibrated $\mathrm{CH}_{3} \mathrm{CO}$ radicals, a step which can readily be shown to be unimportant here because of the huge radical concentration and the resulting predominance of radical recombinations. (Similarly, reaction of thermal $\mathrm{CH}_{3}$ 's with acetone to form $\mathrm{CH}_{4}$ can be excluded here.)

The independence of $\mathrm{C}_{2} \mathrm{H}_{6} / \mathrm{CO}$ ratio and, hence, of biacetyl/CO ratio ${ }^{12}$ of light intensity, and the decrease in $\mathrm{C}_{2} \mathrm{H}_{6} / \mathrm{CO}$ ratio with increasing pressure are consistent with steps (1) and (2), (2a) having been established by low-intensity studies.

$$
\begin{aligned}
\left(\mathrm{CH}_{3}\right)_{2} \mathrm{CO}+h \nu \rightarrow\left(\mathrm{CH}_{3}\right)_{2} \mathrm{CO}^{*} \rightarrow & \mathrm{CH}_{3}+\mathrm{CH}_{3} \mathrm{CO} \\
& \rightarrow\left(\mathrm{CH}_{3}\right)_{2} \mathrm{CO},
\end{aligned}
$$

where $M$ is any colliding molecule,

This trend of ratio with pressure was also found at low intensities, ${ }^{6}$ the study being performed at constant absorbed intensity to counteract the intensity effect on thermal reactions noted earlier but absent here. However, under low-intensity conditions wall effects can occur, and one explanation previously offered for the pressure trend was based on an increased acetone

"We are greatly indebted to Professor H. I. Schiff of McGill University for these analyses.

12 In unpublished studies in this laboratory, A. Shilman has found this ratio to equal approximately $\left(\mathrm{C}_{2} \mathrm{H}_{6} / \mathrm{CO}-1\right)$. See footnote 5 . pressure's causing a decreased diffusion of acetyl radicals to the wall. At the wall they were assumed to recombine to form biacetyl. Wall effects are absent under flash conditions, so such an explanation is not applicable here: The radical concentration is so high at flash intensities that the radical may be estimated to diffuse only about $0.01 \mathrm{~cm}$ at $100 \mathrm{~mm}$ gas pressure before it recombines. ${ }^{13}$ It therefore has a negligible chance of reaching the wall. Another complicating pressure effect sometimes present at low intensities but absent here involves diffusion of radicals out of the light beam, thereby decreasing their average concentration and increasing the relative importance of first-order processes. ${ }^{14}$

The independence of $\mathrm{CH}_{4} / \mathrm{CO}$ of incident light intensity ${ }^{15}$ and acetone pressure shows that the $\mathrm{CH}_{4}$, too, arises either in a primary act or from one species which does not undergo competitive reactions of different orders. The first possibility, an intramolecular formation of $\mathrm{CH}_{4}$ and $\mathrm{CH}_{2} \mathrm{CO}$, was eliminated by the results of our acetone-acetone- $d_{6}$ experiments, whose random mixing results established a free radical origin of the methanes. (In an intramolecular formation, only $\mathrm{CH}_{4}$ and $\mathrm{CD}_{4}$ would be formed.) Again, we believe that we have established that the bulk of the methane does not arise here from a disproportionation between thermally equilibrated $\mathrm{CH}_{3}$ 's and $\mathrm{CH}_{3} \mathrm{CO}$ 's, for in that case the $\mathrm{CH}_{4} / \mathrm{CO}$ would decrease appreciably with increasing acetone pressure, which it does not. ${ }^{5,16} \mathrm{Ac}-$ cordingly, we infer that the $\mathrm{CH}_{4}$ arises from a hot methyl radical (or hot acetyl reacting with methyl). This mechanism is easily shown to be consistent with a $\left.\left(\mathrm{CH}_{4}\right)\left(\mathrm{CD}_{4}\right) / \mathrm{CH}_{3} \mathrm{D}\right)\left(\mathrm{CD}_{3} \mathrm{H}\right)$ ratio of about unity in the absence of isotopic effects. Even including isotopic effects some cancellation of the effects would be expected in this overall ratio, with a result which would approach unity.

The wavelength effect on the $\mathrm{C}_{2} \mathrm{H}_{6} / \mathrm{CO}$ ratio is striking. The ratio increases with decreasing wavelength in the pressure range studied. Data in the literature obtained in this pressure range at the higher low intensities and at two different wavelengths are summarized in Table II. The same trend appears to exist, ${ }^{17}$ though not unequivocally. The maximum intensity in

13 The distance, $x$, is $\left(2 D_{\tau}\right)$, and $\tau$, the lifetime of a radical, $=$ $1 /(k R / t)^{t}$ so that $x=\left(4 D^{2} / / k R\right)^{1 / 4}$ where $R$ is the biacetyl formation per unit volume, $t$ is the flash time, $3 \times 10^{-4} \mathrm{sec}^{4}$, and $k$ is the recombination constant, assumed here as a first approximation to be of the order of that ${ }^{1}$ for $\mathrm{CH}_{3}$ radicals.

${ }^{14}$ W. A. Noyes and L. Dorfman, J. Chem. Phys. 16, 788 (1948); A. J. C. Nicholson, J. Am. Chem. Soc. 73, 3981 (1951).

${ }_{15} \mathrm{Cf}$. same independence of ratio on $I_{0}$ and same value of ratio at high "low intensities," P. Ausloos and E. W. R. Steacie, Can. J. Chem. 33, 47 (1955).

${ }_{16}\left(\mathrm{CH}_{3}\right) \propto\left(\mathrm{C}_{2} \mathrm{H}_{6}\right)^{3}$ and $\left(\mathrm{CH}_{3} \mathrm{CO}\right) \propto\left(\mathrm{C}_{2} \mathrm{H}_{8}-\mathrm{CO}\right)^{\frac{1}{2}}$, therefore $R_{\mathrm{CH}} / R_{\text {CO }}$ would be proportional to

$$
\left\{\left(\mathrm{C}_{2} \mathrm{H}_{6} / \mathrm{CO}\right)\left[\left(\mathrm{C}_{2} \mathrm{H}_{6} / \mathrm{CO}\right)-1\right]\right\}^{3},
$$

where $\mathrm{C}_{2} \mathrm{H}_{6}$ denotes the ethane formed, etc.

${ }_{17}$ An opposite trend at this pressure has been observed under different conditions (e.g., lower intensities). See work cited in footnote 6 . 
Table II. Acetone photolysis at low intensities and approximately $150 \mathrm{~mm}$ acetone.

\begin{tabular}{|c|c|c|c|c|}
\hline Authors & $\begin{array}{l}\text { Relative } \\
\text { intensity }\end{array}$ & $\begin{array}{c}250-270 \\
\mathrm{~m} \mu \\
\mathrm{C}_{2} \mathrm{H}_{6} / \mathrm{CO}\end{array}$ & $\begin{array}{l}\text { Relative } \\
\text { intensity }\end{array}$ & $\begin{array}{c}300+ \\
\mathrm{m}_{\mu} \\
\mathrm{C}_{2} \mathrm{H}_{6} / \mathrm{CO}\end{array}$ \\
\hline $\begin{array}{l}\text { Steacie and } \\
\text { Darwent }\end{array}$ & 20 & 2.2 & 3 & 1.4 \\
\hline Spence and Wildc & $\begin{array}{r}10 \\
2\end{array}$ & $\begin{array}{l}2.4 \\
2.2\end{array}$ & 2 & $1.2 \pm 0.2$ \\
\hline $\begin{array}{l}\text { Howland and } \\
\text { Noyes }^{\mathbf{d}}\end{array}$ & $3,0.3$ & 1.4 & 1 & 1.2 \\
\hline
\end{tabular}

Rounded figures.

b E. W. R. Steacie and B. de B. Darwent, J. Chem. Phys. 16, 230 (1948).

c R. Spence and W. Wild, J. Chem. Soc. 1941, 590.

d J. J. Howland and W. A. Noyes, J. Am. Chem. Soc. 66, 974 (1944).

Table II is about $10^{5}$ less than ours in the same wavelength range.

The present data may be compared with those obtained by Roebber et al. ${ }^{5}$ Their $\mathrm{C}_{2} \mathrm{H}_{6} / \mathrm{CO}$ ratio was intensity-dependent, as here. The $\mathrm{C}_{2} \mathrm{H}_{6} / \mathrm{CO}$ ratio de- creased with increasing pressure, as here, and their $\mathrm{C}_{2} \mathrm{H}_{6} / \mathrm{CO}$ approximately equals ours in the $280 \mathrm{~m} \mu$ range. A major difference, however, is that their $\mathrm{CO}$ quantum yield increased with increasing pressure while ours in Table Ia does not, a point which merits further investigation.

\section{ACKNOWLEDGMENT}

The authors are pleased to acknowledge the support of this research by the United States Air Force WADC and Office of Scientific Research.

Note added in proof. In subsequent work by Mr. A. Shilman in this laboratory, an extensive investigation has been made of pressure effects near 260,280 , and $300 \mathrm{~m} \mu$. Near $260 \mathrm{~m} \mu$ and near $300 \mathrm{~m} \mu$, the CO quantum yield was pressure-independent. Near $280 \mathrm{~m} \mu$, it was pressure-dependent in agreement with Roebber et al. ${ }^{5}$ Thus, the difference between Roebber's results at 280 $\mathrm{m} \mu$ and those obtained at low light intensities ${ }^{6-8}$ (usually at 254 and $313 \mathrm{~m} \mu$ ) appear to represent wavelength effects.

\title{
Electrical Conductivity of Near-Stoichiometric $\alpha-\mathrm{Nb}_{2} \mathrm{O}_{5} \dagger$
}

\author{
E. H. Greener, * D. H. Whitmore, AND M. E. Fine \\ Department of Materials Science, Northwestern University, Evanston, Illinois
}

(Received June 29, 1960)

\begin{abstract}
The electrical conductivity of $\alpha-\mathrm{Nb}_{2} \mathrm{O}_{5}$ monocrystalline and sintered specimens, measured under a constant ambient oxygen pressure and over the temperature range 300 to $900^{\circ} \mathrm{C}$, exhibits an exponential temperature dependence with an activation energy of $1.65 \mathrm{ev}$. The isothermal conductivity, $\sigma$, of near-stoichiometric $\alpha-\mathrm{Nb}_{2} \mathrm{O}_{5}$ is related to the ambient oxygen partial pressure, $P_{\mathrm{O}_{2}}$, by the power law expression $\sigma=$ const $P_{\mathrm{O}_{2}}{ }^{-0.24 \pm 0.01}$. Both sets of observations may be rationalized on the basis that slightly-reduced $\alpha-\mathrm{Nb}_{2} \mathrm{O}_{5}$ becomes a metal-excess, $n$-type semiconducting oxide containing oxygen vacancies capable of trapping electrons. A detailed analysis of the relation between conductivity and ambient oxygen pressure has indicated that the conductivity dependency may be ascribed to a mechanism whereby defect levels (due to oxygen ion vacancies with either one or two trapped electrons) are created and electrons are thermally excited from these levels into the conduction band.
\end{abstract}

\section{INTRODUCTION}

$\mathbf{T}$ HE potential use of niobium for high temperature service has focused attention on its oxides since these make up the barrier layer between the metal and gas phase during oxidation. Unfortunately little is known about the properties of these materials. Brauer ${ }^{1}$ found that $\alpha-\mathrm{Nb}_{2} \mathrm{O}_{5}$ could exist as a single phase with departures from stoichiometry up to $\mathrm{Nb}_{2} \mathrm{O}_{4.8}$. $\mathrm{He}$ also

† This research was supported by the Department of Navy, Office of Naval Research.

* Present address: Assistant Professor of Mathematical Engineering, Marquette University, Milwaukee, Wisconsin.

1 G. Brauer, Z. anorg. u. allgem. Chem. 248, 1-34 (1941). indexed the first x-ray powder patterns of this material, but was unable to solve the crystal structure. Later investigators ${ }^{2,3}$ found $\alpha-\mathrm{Nb}_{2} \mathrm{O}_{5}$ to be monoclinic, but were not able to agree on lattice dimensions. While $\mathrm{Nb}_{2} \mathrm{O}_{5}$ may be prepared with two or more structures by transformation at different temperatures, the transformation to the $\alpha$ modification occurs on heating to $1100^{\circ} \mathrm{C}$ and is irreversible on cooling below this temperature. The lattice parameters of $\alpha-\mathrm{Nb}_{2} \mathrm{O}_{5}$ according to Holtzberg $e t a l^{2}$ are listed in Table I.

${ }^{2}$ F. Holtzberg, A. Reisman, M. Berry, and M. Berkenblit, J. Am. Chem. Soc. 79, 2039-2041 (1957).

${ }^{3}$ M. W. Shafel and R. Roy, Z. Krist. 110, 241 (1951). 